\title{
Attentional bias moderates the link between attachment-related expectations and non-
}

suicidal self-injury

Laurence Claes $^{1,2}$, Rudi De Raedt ${ }^{3}$, Magali Van de Walle ${ }^{1}$, \& Guy Bosmans ${ }^{1}$

${ }^{1}$ Faculty of Psychology and Educational Sciences, KU Leuven, Leuven, Belgium

${ }^{2}$ Faculty of Medicine and Health Sciences, University of Antwerp, Antwerp, Belgium

${ }^{3}$ Department of Experimental Clinical and Health Psychology, Ghent University, Ghent, Belgium

RUNNING HEAD: Attentional bias moderates link between attachment-related expectations and NSSI

\section{Corresponding author}

Laurence Claes

KU Leuven, Faculty of Psychology and Educational Sciences

Tiensestraat 102, box 3720

3000 Leuven

Belgium

Laurence.claes|@ppw.kuleuven.be / Phone: +32 16 32.61.33 / Fax: +32 16 32.59.16

Authors Claes, De Raedt, Van de Walle and Bosmans declare that they have no conflict of interest.

All procedures performed in studies involving human participants were in accordance with the ethical standards of the institutional and/or national research committee and with the 1964 Helsinki declaration and its later amendments or comparable ethical standards. 


\begin{abstract}
Insecure attachment is a transdiagnostic risk factor for the development of emotional and behavior problems. In the present study, we investigated the association between attachmentrelated expectations and non-suicidal self-injury (NSSI) in a sample of 42 university students, taking into account the attentional bias around mother as a mechanism to explain this association. All participants completed the Self-Harm Inventory to assess life-time NSSI and the Inventory of Parent and Peer Attachment and the Attentional Breadth Task. Overall, $28.6 \%$ of the participants engaged in at least one type of life-time NSSI. The results showed that participants who are less able to trust their mother are less likely to communicate with her, which is linked to more life-time NSSI, but only when their attention is more focused on her. Therefore, from a clinical point of view, it is advisable to also focus on the child-parent interaction while preventing or treating NSSI in adolescents and young adults.
\end{abstract}

Keywords: Attachment, Non-Suicidal Self-Injury, Attention 


\section{Introduction}

According to attachment theory, securely attached individuals recurrently experienced that parents were sensitive and responsive caregivers and, consequently, developed trust that they can rely on these parents as sources of support and care during distress. Instead, insecurely attached individuals would have experienced less sensitive and responsive care and consequently remained uncertain that they can rely on parental care and response during distress (Bowlby, 1969). Accumulating evidence suggests that, across the life-span, insecure attachment is a transdiagnostic risk factor for the development of emotional and behavior problems (e.g., Deklyen \& Greenberg, 2008) including non-suicidal self-injury (NSSI) (Bureau et al., 2010; Di Pierro, Sarno, Perego, Galluci, \& Madeddu, 2012; Gormley \& McNeil, 2010; Hilt, Nock, Lloyd-Richardson, \& Prinstein, 2008; Kaess et al., 2013; Yates, Tracy, \& Luther, 2008).

Non-suicidal self-injury refers to the deliberate and direct injury to one's own body tissue without suicidal intent, such as scratching, cutting, and burning oneself (Claes \& Vandereycken, 2007). Prevalence rates of NSSI among college students range from $17 \%$ to $38 \%$ (Whitlock et al., 2011). Although some studies show NSSI to be more common in females, a number of studies show no difference in prevalence in males and females (Whitlock et al., 2011). The average age of onset of NSSI in college students was estimated around 15.2 years (Whitlock et al., 2011). Due to high lifetime prevalence rates of NSSI, combined with physical, mental health and social implications, NSSI has emerged as a major public health concern.

NSSI often serves intrapersonal and interpersonal functions (such as emotion regulation, cry for help; Klonsky, 2009; Nock \& Prinstein, 2004). Concerning interpersonal factors, NSSI is often related to interpersonal trauma, parental invalidation and attachmentrelated problems (Linehan, 1993; Yates, 2004). Several studies in adolescents and young 
adults have shown that insecure attachment, measured with the Inventory of Parent and Peer Attachment (IPPA; Armsden \& Greenberg, 1987) is related to an increased risk to engage in NSSI. Hilt et al. (2008), for example, investigated 508 sixth, seventh and eighth graders and found that adolescents who engaged in NSSI reported lower parental relationship quality (IPPA total score) compared to those without NSSI. Similarly, Bureau et al. (2010) investigated 1238 university students with and without NSSI using the IPPA, and reported that students with NSSI reported less trust, less communication and more alienation in the relationship with their mother compared to students without NSSI. Although all these studies confirm the association between insecure attachment and NSSI, less is known about the mechanisms that underlie this relationship.

To explain this relationship, one can suppose that uncertainty about the availability of the attachment figure decreases the likelihood that insecurely attached individuals use their attachment figures as a resource to help regulate distress (Bosmans, Braet, Heylen, \& De Raedt, 2015) and increases the use of maladaptive coping strategies (Brumariu, 2015). Specifically, attachment-related expectations determine whether or not individuals communicate with their attachment figures about their experiences (Bosmans, Dujardin, Raes, \& Braet, 2013). Because lack of parent-child communication is related to psychopathology, one could predict that the link between decreased trust in attachment figure availability and NSSI, is mediated by the extent to which individuals communicate with their attachment figures. In support of this assumption, research suggests that lack of communication with primary caregivers is a central risk factor in the development of NSSI because NSSI can be used as a non-verbal strategy to elicit the care of the attachment figure (see Nock \& Prinstein, 2004).

Additionally, recent research has demonstrated that the maladaptive effect of insecure attachment reflects the interplay between strategic and automatic attachment processes 
(Bosmans, Koster, Vandevivere, Braet, \& De Raedt, 2013; Steele, 2015). Strategic attachment processes reflect individuals' deliberate evaluation of whether or not they can trust in their attachment figures' availability. Automatic attachment processes occur outside of individuals' strategic control. One example is the automatic narrowing of individuals' attentional field around stimuli that are source of anxiety and worry (Derryberry \& Tucker, 1994; Easterbrook, 1959). Applied to attachment, research shows that children who are concerned about whether or not mother is available for support have a more narrow attentional field around their mother (Bosmans, Braet, Koster, \& De Raedt, 2009). Investigating the interaction between these strategic and automatic processes, Bosmans et al. (2013) showed in two separate samples that children who strategically report less trust in maternal support, but who have at the same time an enhanced automatic attentional focus on their mother, display most behavioral and emotional problems. This suggests that uncertainty in maternal support has a more maladaptive effect in those children who are actually focused on mother. In line with the transdiagnostic nature of insecure attachment, one could predict that individuals who report less trust in maternal support would be most vulnerable to display NSSI when they have an enhanced attentional focus on their mother.

The extent to which individuals perceive themselves as communicating more or less with their attachment figures can be again considered a strategic process. Therefore it seems reasonable to additionally predict an interaction between communication and the breadth of individuals' attentional field around their attachment figure on NSSI. Such an effect would indicate that individuals who report to communicate less with their attachment figure more often engage in NSSI when they are automatically driven to focus their attention more on their attachment figure.

Finally, because theory suggests that communication is the mechanism that might explain the link between lack of trust in attachment figure support and NSSI, and because we 
predicted that the effect of lack of communication might be most strongly linked to NSSI in those individuals with a more narrow automatic attentional field around the attachment figure, we formulated the hypothesis that the mediating effect of communication in the link between trust and NSSI will be moderated by automatic attentional narrowing around mother (see Figure 1). This would suggest that individuals who lack trust in the availability of the attachment figure's support are less likely to communicate with their attachment figure, which is linked to more NSSI, but only when their attentional field on their attachment figure is automatically narrowed as an indication of the extent to which they are focused on their attachment figure.

In summary, the aim of this present study is fourfold: First, we investigated whether the link between decreased trust in mother (the attachment figure in the present study) and life-time NSSI is mediated by the extent to which individuals communicate with their mother. As we know from research, attachment-related expectations (trust or not) determine whether or not individuals communicate with their mother about their experiences (see Dujardin et al., 2015a,b). Secondly, given that psychopathology outcomes relate most strongly to attachment trust in individuals with enhanced attentional focus on mother, we investigated whether individuals who report less trust in maternal support mention more life-time NSSI when they have an enhanced attentional focus on their mother. Third, research suggests that NSSI is a non-verbal communication strategy to elicit the care of the mother (Nock \& Prinstein, 2004). Consequently, it seems reasonable to assume that an increased attentional focus on mother in individuals who communicate less with mother is related to more life-time NSSI. Finally, we investigated whether trust in maternal support provides the relational context in which students who are less able to communicate with their mother and who have an enhanced attentional focus on mother report more life-time NSSI, given that NSSI can be used to elicit proximity to the caregiver who is expected to be unavailable. 


\section{Method}

\section{Participants}

The current sample consisted of 42 university students, of whom $71.4 \%(n=30)$ were female and $28.6 \%(n=12)$ were male. The mean age of the students was 22.76 years $(S D=$ 1.36; range 19-25 years), with no significant gender difference in age $[F(1,40)=0.214, p=$ $.65]$.

\section{Measures}

Non Suicidal Self-Injury: Participants completed an adapted Dutch version of the Self-Harm Inventory (SHI; Sansone, Wiederman, \& Sansone, 1998) which consists of 22 yes/no items inquiring whether the participant had "ever intentionally, or on purpose" engaged in the specified behavior (e.g., cutting). Students also indicated whether or not the behaviors endorsed were displayed with(out) suicidal intent. Only behaviors endorsed as nonsuicidal in intent were included in the analyses. For the purpose of present study only the NSSI subscale (cutting, burning, hitting, scratching and head-banging, preventing wounds from healing, other type of NSSI; Sansone, Songer, \& Sellbom, 2006) was used, with an internal consistency of $\alpha=0.68$ for the current sample.

Attentional Breadth around Mother: The Attentional Narrowing Effect was measured using the Attentional Breadth Task (ABT, Bosmans et al., 2009, 2013; Dewitte \& Koster, 2012). Participants were seated in front of a 19', CRT-computer screen, at a distance of exactly $27 \mathrm{~cm}$ from the screen using a chin rest to ensure accurate positioning and a computer mouse for answering. Each trial (see Figure 2), a picture of $3 \times 4 \mathrm{~cm}$ appeared on the center of the screen. This picture was either a picture of the mother or a picture of an unfamiliar woman. Ten different pictures of the mother were taken by the participant using a digital photo camera, focusing on the mother's face, and avoiding bright colors in the pictures. 
The mother was asked to pose with a neutral face, without showing her teeth to avoid salience effects. Next, ten pictures of 10 different unfamiliar women were taken prior to the study. Simultaneously with the presentation of the central picture, 16 gray dots with a diameter of 2 $\mathrm{cm}$ appeared at $4.5 \mathrm{~cm}$ from the central picture (close trials at $10^{\circ}$ of the visual angle) and at $11.2 \mathrm{~cm}$ from the central picture (far trials at $25^{\circ}$ ) The grey dots were arranged in pairs of two (one close and one far dot, situated on one of eight imperceptible axes that came together in the central point were the central picture was shown). Together with the dots, a smaller black circle (diameter of $1.3 \mathrm{~cm}$ ) appeared either in one of the close or in one of the far dots. This black circle was the target stimulus that participants had to identify. Participants were instructed to look at the centre of the screen to identify the central picture and the target stimulus. After each stimulus presentation a second screen appeared with the question which picture they had seen (mother or unfamiliar woman). Then a third screen appeared with the question on which of eight axes the target stimulus was located.

Four categories of stimuli were presented: two picture types (mother versus unfamiliar women) combined with two distances (target stimulus presented close or far from the central picture). Each category contained 16 trials. The trials were presented in random order in two blocks of 64 trials each, which were preceded by 10 practice trials and separated by a short break. In the first block stimuli were presented at $250 \mathrm{~ms}$ and in the second block at $68 \mathrm{~ms}$. In our study, only the trials with stimulus presentations at $68 \mathrm{~ms}$ were used. This presentation time was needed to prevent the outcomes from being affected by eye-saccades that occur at approximately $90 \mathrm{~ms}$, which ensured that we were measuring the breadth of the attentional field around the central pictures (automatic attentional processes) instead of attentional scanning abilities.

For all analyses, only the trials with correctly identified central pictures were used. This ensures that attention was focused to the middle of the screen. The proportion of 
correctly identified targets on trials with correctly identified pictures served as the main variable. An Attentional Narrowing Index (ANI) was calculated by subtracting the proportion of correctly identified targets on the far trials from the proportion of correctly identified targets on the close trials. The ANI was calculated for mothers (ANImother) and unfamiliar women (ANIunfamiliar). Finally, the attentional narrowing effect (ANE) was calculated subtracting ANIunfamiliar from ANImother. ANE expresses the extent to which the attentional focus on mother is enhanced compared to the attentional focus on unfamiliar women. Higher ANE scores suggest an enhanced attentional focus on mother.

Attachment-related Expectations: The Inventory of Parent and Peer Attachment (Armsden \& Greenberg, 1987), which assesses Trust in the attachment figures' support, Communication about distress, and Alienation from the attachment figure, was used to assess attachment-related expectations. The Trust scale measures the degree of mutual understanding and respect in the attachment relationship ( 4 items, $\alpha=.78$ for the current sample), the Communication scale assesses the extent and quality of spoken communication ( 4 items, $\alpha=$ $.87)$ and the Alienation scale assesses feelings of anger and interpersonal alienation (4 items, $\alpha=.62$ ). Because of the lower reliability of the Alienation scale and because this scale was not relevant for the current study's hypotheses, this scale was dropped from the analyses. For the current study, only the items of the scales focusing on the relationship with mother were used. Participants responded on a 4-point Likert-scale ranging from 1 (almost never true) to 4 (almost always true). This measure has been widely used, has good psychometric properties, and has shown good validity in adolescents (Allen, in press).

\section{Procedure}

The participants were collected by an oral of written invitation published on Facebook by graduate students. Next, volunteering participants were informed about the content of the study and were asked approval to participate. All participating students gave their informed 
consent. Prior to administration of the questionnaires, the participants completed the ABT, after the photos of their mother were integrated into the ABT. All participants were tested individually. The ethical committee of the Faculty of Psychology and Educational Sciences approved the study, in accordance with the ethical standards as laid down in the Declaration of Helsinki (1964).

\section{Results}

Overall, $28.6 \%(n=12)$ of the students engaged at least in one type of NSSI during lifetime. Sixty-seven percent $(n=8)$ of the participants engaged in only one type of NSSI, whereas $33.3 \%$ engaged $(n=4)$ in at least two types of NSSI. Scratching oneself was the most common type of NSSI $(n=7,16.7 \%)$, followed by head banging $(n=5,11.9 \%)$, cutting oneself $(n=4$; 9.5\%), hitting $(\mathrm{n}=1,2.4 \%)$, burning $(\mathrm{n}=1,2.4 \%)$, preventing wounds from healing $(\mathrm{n}=0)$ and other type of NSSI $(n=3,7.1 \%)$. Students belonged to the NSSI group if they had ever engaged in at least one type of NSSI. The mean age of onset of NSSI was 14.36 years $(S D=$ 1.29; range 12-16 years). Overall, the prevalence of NSSI was not significantly different between male and female participants $\left[\chi^{2}(1)=3.780, p=.05\right]$, and students with NSSI did not differ in age from students without NSSI $[F(1,40)=0.081, p=.78]$.

Concerning the results of the MANOVA with the attachment-related expectations (two IPPA scales) as dependent variables and the presence/absence of life-time NSSI as independent variable, students with NSSI scored significantly different on the IPPA scales compared to students without NSSI [Wilks' $\lambda=0.798 ; F(2,39)=4.933 ; p=.01 ;$ Partial $\eta^{2}=$ 0.202]. More specific, students with NSSI scored significantly lower on Communication compared to students without NSSI (see Table 1). The correlation between Communication and Trust was $r=.72(p<.001)$. 
To investigate whether Communication mediates the association between Trust and life-time NSSI (Hypothesis 1) a mediation analysis was performed. Given the small sample size, we used a nonparametric resampling method (Preacher \& Hayes, 2004, 2008) with 1000 resamples drawn with replacement from the original sample to derive the $95 \%$ confidence interval (CI) for the indirect effect. To that end, we used the SPSS macro PROCESS (Model 4) provided by Preacher and Hayes $(2004,2008)$. The results showed that the relationship between Trust and NSSI is mediated by Communication. More specific, more Trust leads to more Communication $(\mathrm{B}=0.72, p<.001,95 \% \mathrm{CI}[.7021 ; 1.3210])$, and more Communication $(\mathrm{B}=-0.51,95 \% \mathrm{CI}[-1.4390 ;-0.0161])$ decreases the probability to engage in NSSI. The indirect effect of communication was estimated to lie between -1.4200 and 0.0496. Because zero is not included in the $95 \%$ CI for the indirect effect, we can conclude that the indirect effect is significantly different from zero at $p<.05$.

To investigate whether the association between Trust and life-time NSSI was moderated by an attentional bias around mother (ANE) (Hypothesis 2), a moderation analysis was performed using Preacher and Hayes' (2014) PROCESS tool for SPSS (Model 1). The results revealed a significant interaction effect between Trust and the attentional bias around mother $(\mathrm{ANE})$ on NSSI $\left(\mathrm{B}=-7.55, \mathrm{SE}_{\mathrm{B}}=3.31, p=.02\right)$. To evaluate the meaning of this interaction effect, data for plotting were generated following the recommendations of Aiken and West (1991), and we performed single slope analysis to assess the significance of the slopes for both the lower and higher values of the moderator (M-1SD, M+1SD). The results showed that students with a more enhanced attentional focus on their mother (ANE) and low Trust in their mother (M-1SD) had a significant higher probability to engage in NSSI compared to students with high Trust in their mother; however, for students with a low attentional focus on mother, the level of Trust did not influence the probability to engage in NSSI (see Figure 3). Additionally, we found significant main effects of Trust and Attentional 
Bias around mother on NSSI. Students with high levels of trust showed a lower probability to engage in NSSI compared to students with lower levels of trust in their mother $(B=-0.70$, $\left.\mathrm{SE}_{\mathrm{B}}=0.33, p=.03\right)$; whereas students with a low attentional focus on mother showed a lower probability to engage in NSSI compared to those with a high attentional focus around mother $\left(\mathrm{B}=114.80, \mathrm{SE}_{\mathrm{B}}=50.06, p=.02\right)$.

A similar analysis was performed to investigate whether the association between Communication and life-time NSSI was moderated by an attentional bias around mother (Hypothesis 3). The results revealed again a significant interaction effect between Communication and the attentional bias around mother on NSSI $\left(\mathrm{B}=-3.53, \mathrm{SE}_{\mathrm{B}}=1.68, p=\right.$ $.04)$. The plot of the interaction term (see Figure 4) displays that students who have a high attentional focus on their mother and who report less communication (M-1SD) with their mother have a significant higher probability to engage in NSSI compared to students who report good communication (M+1SD) with their mother; however, for students with a low attentional focus around their mother, the quality of communication does not influence the probability to engage in NSSI. Additionally, we found significant main effects of Communication and Attentional Bias around mother of NSSI. Student with high levels of communication with their mother showed a lower probability to engage in NSSI compared to students with lower levels of communication with their mother $\left(\mathrm{B}=-0.60, \mathrm{SE}_{\mathrm{B}}=0.25, p=\right.$ $.02)$; whereas students with a low attentional focus around mother showed a lower probability to engage in NSSI compared to those with a high attentional focus around mother $(B=45.55$, $\left.\mathrm{SE}_{\mathrm{B}}=20.35, p=.03\right)$.

Finally, to investigate whether trust in mother's support provides the relational context in which students who are less able to communicate with their mother and who have an enhanced attentional focus on their mother might increase the likelihood that NSSI is linked with communication to elicit proximity from mother, we performed a moderated mediation 
analysis using Hayes' (2013) PROCESS tool for SPSS (Model 14). The result of this analysis showed a significant positive association between Trust in mother and Communication with mother $(r=.72, p<.001)$ and the mediating effect of Communication in the link between Trust and NSSI was moderated by the attentional focus on mother $\left(\mathrm{B}_{\text {interaction }}=-3.64, \mathrm{SE}_{\mathrm{B}}=\right.$ $1.78, p=.04)$. Communication mediated the link between Trust and NSSI when participants had an enhanced attentional focus on mother $(B=-1.2052$, Boot SE $=1.5986,95 \%$ CI [$3.3204 ;-0.2627])$, but not when participants were less attentionally focused on mother $(\mathrm{B}=$ 0.0636, Boot SE $=1.0959,95 \%$ CI $[-1.9166,1.8362])$. Students with an enhanced attentional focus on mother and a lower level of communication with their mother had a higher probability to engage in NSSI compared to students with a higher level of communication with their mother. For students with no enhanced attentional focus on mother, the level of communication did not influence the probability to engage in NSSI, confirming our hypothesized model in Figure $1^{1}$.

\section{Discussion}

In the present study, we investigated the association between current attachmentrelated expectations and life-time NSSI in a sample of university students, taking into account the attentional bias around mother as a mechanism to explain this association. Overall, 28.6\% of the university students engaged in at least one type of NSSI during life-time, with a mean age of onset of 14.36 years, and no significant differences between male and female students. The most prevalent types of NSSI were head banging, scratching, and cutting oneself; confirming the findings of Whitlock et al. (2011).

Concerning the relationship between current attachment-related expectations and lifetime NSSI, we found that university students with NSSI show lower scores on communication

\footnotetext{
${ }^{1}$ The same analyses were performed with the $250 \mathrm{~ms}$ trials; however, none of the analyses revealed significant results.
} 
compared to students without NSSI. So, in line with earlier studies (e.g., Bureau et al., 2010; Hilt et al., 2008) we could confirm the association between insecure attachment and NSSI. Although the aforementioned association between insecure attachment and NSSI has been confirmed in many studies, research on the mechanisms that underlie this relationship is still scarce, which was the aim of the present study.

First, we investigated whether the association between Lack of Trust and life-time NSSI was mediated by Lack of Communication. This first hypothesis was confirmed in our study. Individuals who trust less in the availability of their attachment figure as a source for support, appear to communicate less with their attachment figures. In turn, this appears to be related to an enhanced risk for displaying life-time NSSI. Second, we investigated whether the association between trust/communication and life-time NSSI is moderated by individuals' automatic attentional processing of the attachment figure (i.c., the mother figure). The results of the current study, supported the hypothesis that participants who have an enhanced attentional focus on their mother, had a higher probability to engage in NSSI during life-time, when they reported less trust and less communication with mother. This finding is in line with the interaction effect between self-reported trust and attachment-related information processing biases in the prediction of behavioral (internalizing and externalizing) problems that was found by Bosmans et al. (2013). They showed that adolescents (10-12 years) who are more uncertain about maternal support and who have - at the same time - a more narrow attentional field around their mother, have the most behavioral problems. The current study adds to these previous findings by demonstrating the trust-attention interaction effect in the explanation of life-time NSSI and by showing that the automatic attentional bias moderates the link between strategic communication and NSSI as well. Moreover, while Bosmans et al.'s (2013) findings were restricted to middle childhood, the current study showed that the same effects could also be found in young adulthood. This is in line with the assumption that 
the attachment system guides similar maladaptive mechanisms across the life-span (Bowlby, 1969).

Finally, the results of our moderated mediation analysis showed that individuals who lack trust in the availability of the attachment figure's support are less likely to communicate with their attachment figure, which is linked to more life-time NSSI, but only when the breadth of their attentional field on the attachment figure is automatically reduced as an indication of the extent to which they are more focused on their attachment figure. If, on the other hand, attention is less focused on the attachment figure, less trust and related reduced communication, seem to reduce individuals' risk to need NSSI to solve distress.

Before discussing the theoretical and clinical implications of these findings, some limitations need to be addressed. First, the study sample is rather small $(\mathrm{N}=42)$ and consists of university students. Future studies, therefore need to replicate the current findings in larger samples, consisting of young adults of community and clinical samples. Second, the study only focused on the attachment relationship with mother, as opposed to both parents; whereas future studies need to include both parents, in order to gain information about overall attachment and potential differences when either the mother or the father is involved. Third, the present study paid attention to the association between strategic/automatic attachment related concepts and life-time presence/absence of NSSI; whereas future studies also need to address the link between attachment and current NSSI or NSSI versatility (i.e., the total number of NSSI in which the participant engages; which is an indicator for NSSI severity). Fourth, the analyses were conducted with cross-sectional data, making it impossible to draw causal conclusions regarding the direction of effects. Finally, in the current study, we investigated the association between attachment related constructs and life-time presence/absence of NSSI, not taking into account other features that could have influenced this association, such as internalizing symptoms like anxiety and depression. Therefore, future 
studies should also include intrapersonal risk factors, such as internalizing symptoms, while investigating the association between interpersonal attachment constructs and NSSI.

Notwithstanding these limitations, this study was the first to take into account the interplay between different components of the attachment system to explain the association between current attachment and life-time NSSI. The current findings nurture an increasing awareness that attachment should be approached as a complex construct where automatic and strategic processes determine developmental outcomes (Bosmans \& Kerns, 2015; Steele, 2015). It also demonstrates the relevance of disentangling different components of this complex construct. The findings suggest that various components of attachment differently relate to a history of life-time NSSI. In line with Bowlby's (1969) and, more recently, Waters and Waters' (2006) proposition that the confidence that the attachment figure is a secure base that can provide support when needed is central in the attachment system, the current results show that trust is a characteristic of the parent-child relationship that is important in understanding communication. Additionally, reduced communication is only linked with increased life-time NSSI if individuals' attention is automatically more focused on mother. Consequently, all components play a specific role and should not be considered in isolation if researchers want to understand why attachment is linked to the development of psychopathology.

The results show that in a context of less trust in the current mother-child relationship, the lack of communication is related to life-time NSSI in participants who have an enhanced attentional focus on their mother. Therefore, from a clinical point of view, it is advisable to also focus on the child-parent interaction while preventing or treating NSSI in adolescents and young adults. Attachment Based Family Therapy (ABFT; Diamond, Reis, Diamond, Siqueland, \& Isaacs, 2002), which focuses on restoring adolescents' and young adults' trust in parental availability and support and on restoring parent-child communication, seems to be a 
promising treatment option for clients who engage in NSSI. It has already been demonstrated that ABFT can be an effective treatment option for depression and suicidality (Bosmans, Vandevivere, \& Krauthamer Ewing, 2013; Diamond et al., 2010), so a future extension to the domain of NSSI seems a valuable option. 


\section{References}

Aiken, L. S., \& West, S. G. (1991). Multiple regression: Testing and interpreting interactions. Newbury Park: Sage.

Allen, J. P. (in press). Assessing attachment in adolescence. In E. Waters, B. Vaughn, \& H. Waters (Eds). Measuring Attachment. New York: Guilford.

Armsden, G. C., \& Greenberg, M. T. (1987). The Inventory of Parent and Peer Attachment: Individual differences and their relationship to psychological well-being in adolescence. Journal of Youth and Adolescence, 16, 427-454.

Bosmans, G., Braet, C., Heylen, J., \& De Raedt, R. (2015). Children's attentional processing of mother and proximity seeking. PLos One. doi: 10.1371/journal.pone.0124038

Bosmans, G., Braet, C., Koster, E., \& De Raedt, R. (2009). Attachment security is linked with attentional breadth in middle childhood. Journal of Clinical Child and Adolescent Psychology, 38, 872-882.

Bosmans, G., Dujardin, A., Raes, F., \& Braet, C. (2013). The specificity of autobiographical attachment memories in early adolescence: The role of mother-child communication and attachment-related beliefs. Journal of Early Adolescence, 33, 710-731.

Bosmans, G., \& Kerns, K. (2015). Attachment in middle childhood: Progress and prospects. New Directions for Child and Adolescent Development, 148, 1-14.

Bosmans, G., Koster, E.H.W., Vandevivere, E., Braet, C., \& De Raedt, R. (2013). Young adolescent's confidence in maternal support: Attentional bias moderates the link between attachment-related expectations and behavioral problems. Cognitive Therapy and Research, 37, 829-839. 
Bosmans, G., Vandevivere, E., \& Krauthamer Ewing, E.S. (2013). Attachment-based family therapy (ABFT): Een evidence-based systeemtherapeutisch behandelprogramma voor depressieve adolescenten [An evidence-based system therapeutic treatment program for depressed adolescents]. In C. Braet \& S. Bogels (Eds.), Protocollaire behandeling voor kinderen met psychische klachten [Mental Health Treatment Protocols for Children] (pp. 179-200). Amersfoort: Boom.

Bowlby, J. (1969). Attachment. London: Penguin Books.

Brumariu, L.E. (2015). Parent-child attachment and emotion regulation. New Directions for Child and Adolescent Development, 148, 31-45.

Bureau, J.-F., Martin, J., Freynet, N., Poirier, A.A., Lafontaine, M.-F., \& Cloutier, P. (2010). Perceived dimensions of parenting and non-suicidal self-injury in young adults. Journal of Youth and Adolescence, 5, 484-494.

Claes, L., \& Vandereycken, W. (2007). Self-injurious behaviour: Differential diagnosis and functional differentiation. Comprehensive Psychiatry, 48, 137-144.

Deklyen, M., \& Greenberg, M.T. (2008). Attachment and psychopathology in childhood. In J. Cassidy \& P.R. Shaver (Eds.), Handbook of attachment: Theory, research, and clinical applications (pp. 637-665). New York: Guilford Press.

Derryberry, D., \& Tucker, D.M. (1994). Motivating the focus of attention. In P.M. Niedenthal \& S. Kitayama (Eds.), Heart's eye: Emotional influences in perception and attention (pp. 167-196). New York: Academic Press.

Dewitte, M., \& Koster, E.H.W. (2012). Attentional breadth and proximity seeking in romantic attachment relationships. British Journal of Social Psychology, 53, 74-92. 
Diamond, G.S., Reis, B.F., Diamond, G.M., Siqueland, L., \& Isaacs, L. (2002). Attachmentbased family therapy for depressed adolescents: A treatment development study. Journal of the Academy of Child and Adolescent Psychiatry, 41, 1190-1196.

Diamond, G.S., Wintersteen, M.B., Brown, G.K., Diamond, G.M., Gallop, R., Shelef, K.\& Levy, S.A. (2010). Attachment-based family therapy for suicidal adolescents: A randomized controlled trial. Journal of the American Academy of Child and Adolescent Psychiatry, 49, 122-131.

Di Pierro, R., Sarno, I., Perego, S., Galluci, M., \& Madeddu, F. (2012). The effects of personality traits, family relationships and maltreatment on the presence and severity of behaviours. European Child and Adolescent Psychiatry, 21, 511-520.

Dujardin, A., Bosmans, G., De Raedt, R., \& Braet, C. (2015b). Attachment expectations and exploration of threatening information in mother's presence. Developmental Psychology, 51, 1341-1350.

Dujardin, A., Santens, T., Braet, C., De Raedt, R., Vos, P., Maes, B., \& Bosmans, G. (2015a). Middle childhood support-seeking behavior during stress: Links with self-reported attachment and future depressive symptoms. Child Development.

Easterbrook, J.A. (1959). The effect of emotion on cue utilization and the organization of behavior. Psychological Review, 66, 183-201.

Gormley, B., \& McNiel, D.E. (2010). Adult attachment orientations, depressive symptoms, anger and self-directed aggression by psychiatric patients. Cognitive Therapy and Research, 34, 272-281. 
Hilt, L.M., Nock, M.K., Lloyd-Richardson, E.E., \& Prinstein, M.J. (2008). Longitudinal study of nonsuicidal self-injury among young adolescents: Rates, correlates, and preliminary test of an interpersonal model. The Journal of Early Adolescence, 28, 455-469.

Kaess, M., Parzer, P., Mattern, M., Plener, P.L., Bifulco, A., Resch, F., \& Brunner, R. (2013). Adverse childhood experiences and their impact on frequency, severity, and individual function of nonsuicidal self-injury in youth. Psychiatry Research, 206, 265-272.

Klonsky, E.D. (2009). The functions of self-injury in young adults who cut themselves: Clarifying the evidence for affect regulation. Psychiatry, 166, 260-268.

Linehan, M. (1993). Cognitive-behavioral treatment of borderline personality disorder. London/New York: Guilford Press.

Nock, M.K., \& Prinstein, M.J. (2004). A functional approach to the assessment of selfmutilative behavior. Journal of Consulting and Clinical Psychology, 72, 885-890.

Preacher, K. J., \& Hayes, A. F. (2004). SPSS and SAS procedures for estimating indirect effects in simple mediation models. Behavior Research Methods, Instruments, and Computers, 36, 717-731.

Preacher, K. J., \& Hayes, A. F. (2008). Asymptotic and resampling strategies for assessing and comparing indirect effects in multiple mediator models. Behavior Research Methods, 40, 879-891.

Sansone, R.A., Wiederman, M.W., \& Sansone, L.A. (1998). The Self-Harm Inventory (SHI): development of a scale for identifying self-destructive behaviors and borderline personality disorder. Journal of Clinical Psychology, 54, 973-983. 
Sansone, R.A., Songer, D.A., \& Sellbom, M. (2006). The relationship between suicide attempts and low-lethal self-harm behavior among psychiatric inpatients. Journal of Psychiatric Practice, 12, 148-152.

Steele, H. (2015). Commentary - Attachment in middle childhood: Looking back, forward, and within. New Directions for Child and Adolescent Development, 148, 99-104.

Waters, H. S., \& Waters, E. (2006). The attachment working models concept: Among other things, we build script-like representations of secure base experiences. Attachment and Human Development, 8, 185-197.

Whitlock, J., Muehlenkamp, J., Purington, A., Eckenrode, J., Barreira, P., Baral-Abrahms, G., Marchell, T., Kress, V., Girard, K., Chin, C., \& Knox, K. (2011). Non-suicidal selfinjury in a college population: General trends and sex differences. Journal of American College Health, 59, 691-698.

Yates, T.M. (2004). The developmental psychopathology of self-injurious behavior: Compensatory regulation in posttraumatic adaptation. Clinical Psychology Review, 24, $35-74$.

Yates, T.M., Tracy, A.J., \& Luthar, S.S. (2008). Nonsuicidal self-injury among “privileged" youths: Longitudinal and cross-sectional approaches to developmental process. Journal of Consulting and Clinical Psychology, 76, 52-62. 
Table 1. Means (standard deviations) of the IPPA scales of students with(out) life-time NSSI

\begin{tabular}{lccccccc}
\hline \multicolumn{2}{c}{ No NSSI } & \multicolumn{2}{c}{ NSSI } & & & \\
& $\mathrm{M}$ & $(\mathrm{SD})$ & $\mathrm{M}$ & $(\mathrm{SD})$ & $F(1,40)$ & $p$ & Partial $\eta^{2}$ \\
& & & & & & & \\
\hline Communication & 12.57 & $(2.81)$ & 9.83 & $(2.86)$ & $8.03 * *$ & .01 & 0.167 \\
Trust & 14.53 & $(2.42)$ & 13.75 & $(1.29)$ & 1.12 & .30 & 0.027 \\
\hline
\end{tabular}


Figure 1: The mediating effect of Communication in the link between Trust and NSSI moderated by Attentional Bias Around Mother

Figure 2: Presentation of the ABT

Figure 3: Interaction between Trust and the Attentional Narrowing Effect (ANE) on the probability to engage in life-time Non-Suicidal Self-Injury

Figure 4: Interaction between Communication and the Attentional Narrowing Effect (ANE) on the probability to engage in life-time Non-Suicidal Self-Injury 
Figure 1

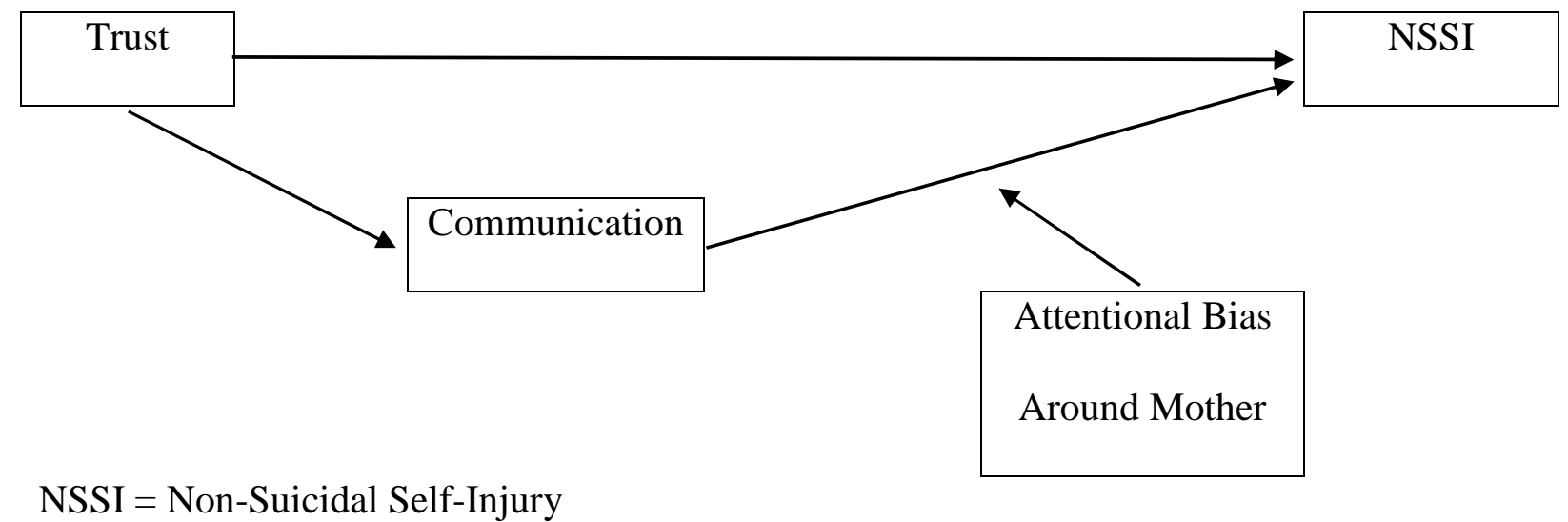


Figure 2 


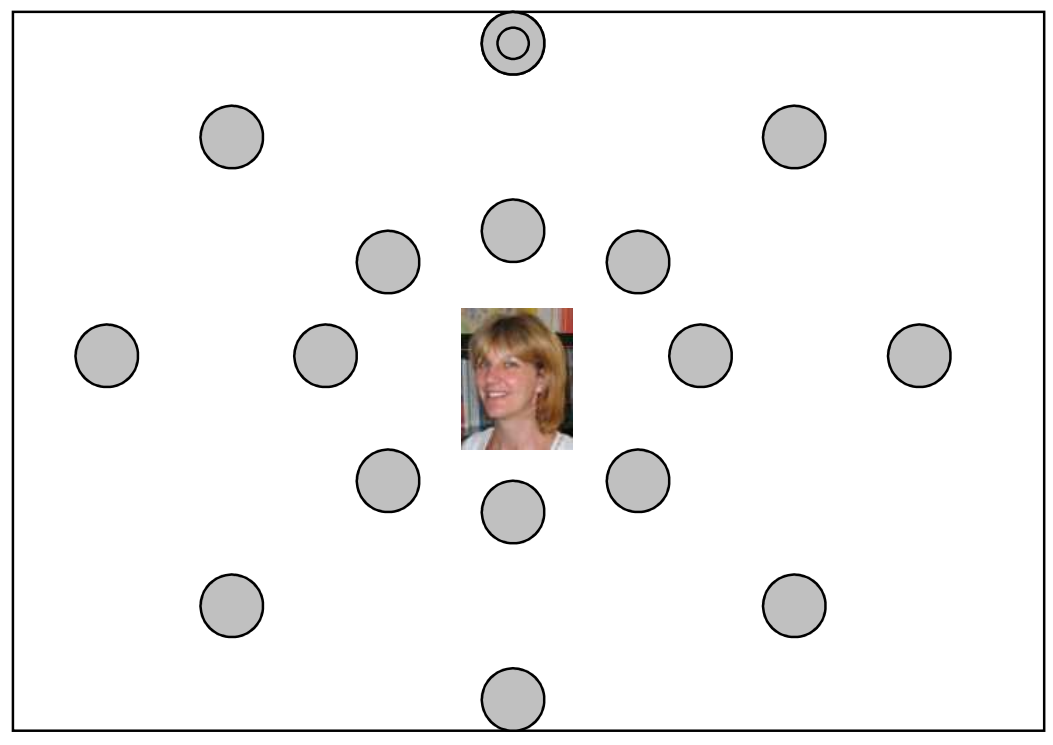

Screen 1 (far trial)

Who did you see in the middle of the screen? Select "1" or "2"

Mother

1
Unfamiliar

2

Screen 2

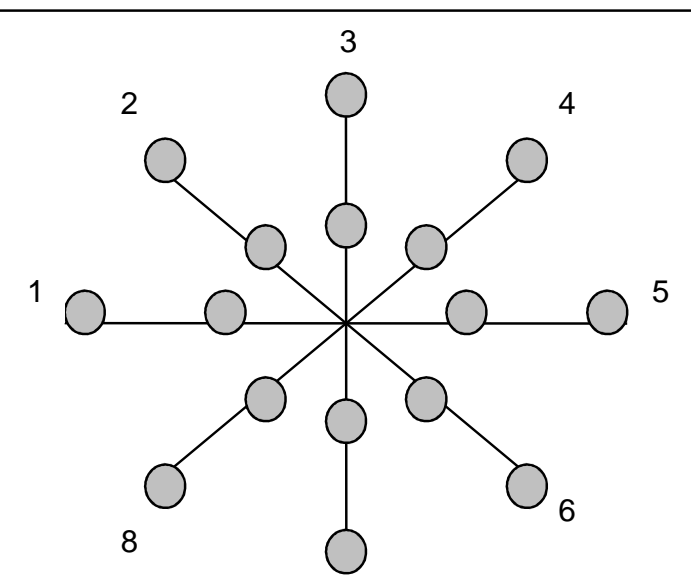

$\begin{array}{lllllllll} & 2 & 3 & 4^{7} & 5 & 6 & 7 & 8\end{array}$

On which axis did the circle appear? Select the corresponding number.

Screen 3 
Figure 3.

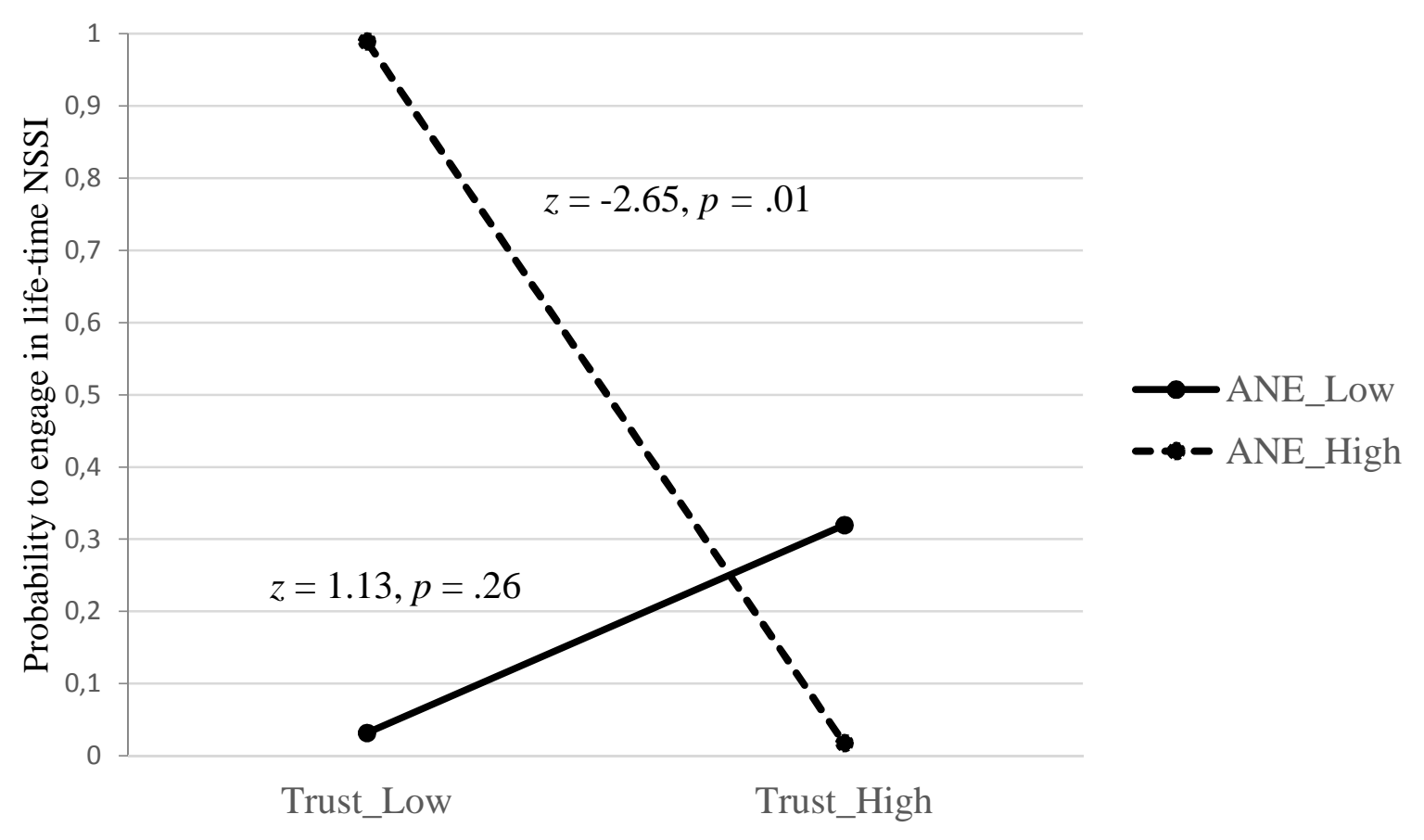


Figure 4.

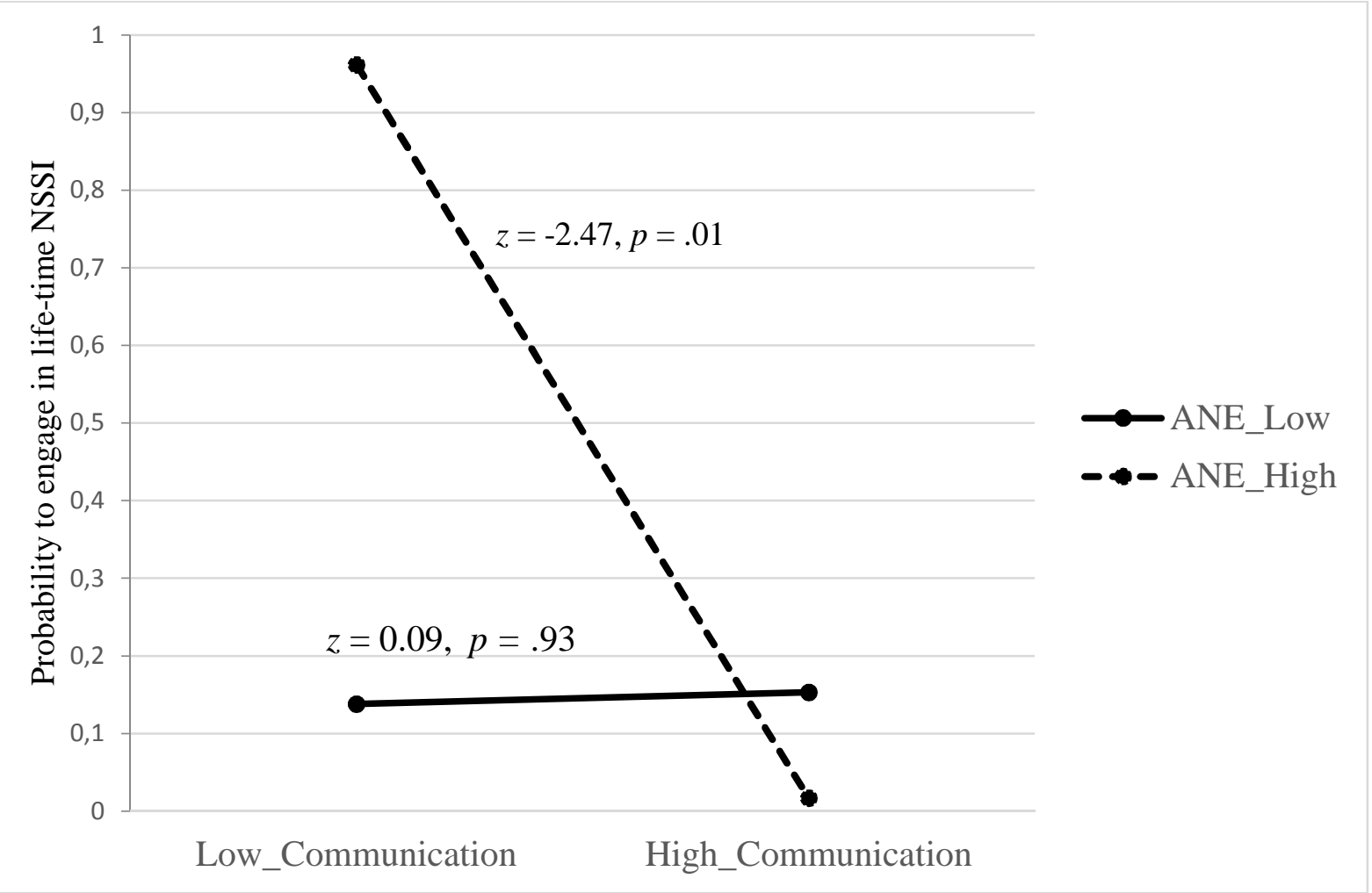




\section{Acknowledgement}

The authors like to thank M. H. and S. W. for their help with the data collection of this study. 